CLINICAL STUDY

\title{
Danish children born with glutamic acid decarboxylase-65 and islet antigen-2 autoantibodies at birth had an increased risk to develop type 1 diabetes
}

\author{
Stefanie Eising ${ }^{1}$, Anita Nilsson ${ }^{2}$, Bendix Carstensen ${ }^{1}$, David M Hougaard ${ }^{3}$, Bent Nørgaard-Pedersen ${ }^{3}$, Jørn Nerup ${ }^{1}$, \\ Åke Lernmark ${ }^{2}$ and Flemming Pociot ${ }^{1,2,4}$ \\ ${ }^{1}$ Hagedorn Research Institute and Steno Diabetes Center, DK-2828 Gentofte, Denmark, ${ }^{2}$ Department of Clinical Sciences, Skåne University Hospital SUS, \\ Lund University/CRC, SE-20502 Malmö, Sweden, ${ }^{3}$ Department of Clinical Biochemistry, Statens Serum Institut, DK-2300 Copenhagen, Denmark and \\ ${ }^{4}$ Glostrup Research Institute, Glostrup University Hospital, Ndr. Ringvej 69, DK-2600 Glostrup, Denmark \\ (Correspondence should be addressed to F Pociot at Glostrup Research Institute, Glostrup University Hospital; Email: fpoc0001@glo.regionh.dk)
}

\begin{abstract}
Objective: A large, population-based case-control cohort was used to test the hypothesis that glutamic acid decarboxylase-65 (GAD65) and islet antigen-2 autoantibodies (IA-2A) at birth predict type 1 diabetes.

Design and methods: The design was an individually matched case-control study of all Danish type 1 diabetes patients born between 1981 and 2002 and diagnosed before May 12004 (median age at diagnosis was 8.8 years). Dried blood spot samples collected 5 days after birth in the 1981-2002 birth cohorts and stored at $-25^{\circ} \mathrm{C}$ were identified from 2023 patients and from two matched controls $(n=4042)$. Birth data and information on parental age and diabetes were obtained from Danish registers. GAD65A and IA-2A were determined in a radiobinding assay. HLA-DQB1 alleles were analyzed by PCR using time-resolved fluorescence.

Results: GAD65A and IA-2A were found in 70/2023 (3.5\%) patients compared to 21/4042 (0.5\%) controls resulting in a hazard ratio (HR) of $7.49(P<0.0001)$. The HR decreased to 4.55 but remained significant $(P<0.0003)$ after controlling for parental diabetes and HLA-DQB1 alleles. Conditional logistic regression analysis showed a HR of $2.55(P<0.0001)$ for every tenfold increase in the levels of GAD65A and IA-2A. This HR decreased to 1.93 but remained significant $(P<0.001)$ after controlling for parental diabetes and HLA-DQB1 alleles.

Conclusion: These data suggest that GAD65A and IA-2A positivity at birth are associated with an increased risk of developing type 1 diabetes in Danish children diagnosed between 1981 and 2004.
\end{abstract}

European Journal of Endocrinology 164 247-252

\section{Introduction}

Type 1 diabetes becomes clinically apparent after a preclinical period of varying length, during which immune-mediated destruction reduces the $\beta$-cell mass. This preclinical period varies but appears to be more rapid in younger individuals (1). Immune-mediated type 1 diabetes is thought to be determined by the actions, and possible interactions, of multiple genetic and environmental factors. At least half of the genetic risk is determined by alleles of the human leukocyte antigen (HLA) genes: DQA1, DQB1, and DRB1 $(2,3)$. The rest is determined by non-HLA loci $(2,3)$. It is still unknown, if, when and what kind of environmental factors initiate autoimmune $\beta$-cell destruction. Viral infections, nutritional, or other factors might initiate the type 1 diabetes pathogenetic process already in utero $(4,5)$ or postnatally (reviewed in (6)). Reflecting $\beta$-cell autoimmunity and possibly destruction, autoantibodies are often detected against glutamic acid decarboxylase65 (GAD65 or GAD2), islet antigen-2 (IA-2), Zn transporter 8 (ZnT8 or SLC30A10), or insulin, alone or in combination (7). The risk for type 1 diabetes increases with an increasing number of autoantibodies, and one or more autoantibodies are detected in about $90 \%$ of newly diagnosed type 1 diabetes patients $(4,8)$.

Because the autoimmune process contributing to the development of type 1 diabetes may be initiated long before the appearance of clinical symptoms (9), ideally effective prediction and intervention strategies should be applied as early as possible. It is still not established whether the presence of islet autoantibodies at the time of birth impacts the development of type 1 diabetes. In recent reports, islet autoantibodies were found to be either protective (10), predictive (4), or without (11) impact on the development of type 1 diabetes.

Current prospective studies of birth cohorts have ascertained only a limited number of new patients per 
year and are expected to take several years to provide sufficient statistical power. Furthermore, in the BABY DIAB (12) and the TRIGR (13) studies, only children with first degree relatives with type 1 diabetes are included but $<15 \%$ of new onset patients belong to this category.

Epidemiological studies indicate that perinatal factors such as gestational infections, pre-eclampsia, birth weight (BW), and maternal age affect the risk for type 1 diabetes $(6,14,15)$. However, in a recent Danish study, no significant correlation between BW, maternal age, and type 1 diabetes risk was detected (16). Owing to the complex nature of type 1 diabetes pathogenesis, combination of immunological and demographical parameters in a large population-based case-control study may improve the identification of factors that predict type 1 diabetes.

The aim of the present study was to estimate the effect of GAD65A and IA-2A at the time of birth on type 1 diabetes risk up to 23 years of age. Interaction between islet autoantibody status and risk alleles (HLA-DQB1), BW, birth length (BL), gestational age (GA), parental age and diabetes status, and age at diabetes onset is tested.

\section{Materials and methods}

\section{Samples}

The study was an individually matched populationbased case-control study (17). All type 1 diabetes cases born in Denmark between January 11981 and December 31 2002, and diagnosed at 23 years or younger, were identified from the National Patient Register. These data were validated against an independent registry (DSBD, www.DSBD.dk) (17). A total of 2023 cases with available dried blood spots (DBSs) samples were identified. The median age at diagnosis was 8.8 years (range 1-22 years). Two control individuals matched by date and place of birth were selected using the databank of DBSs (see below). Control individuals were required to be alive and free of diabetes at the date of diagnosis of the matching cases. Information on parental diabetes status (at the time of delivery), including type of diabetes, was obtained from the National Patient Registry, and information on birth data (BW, BL, and GA) was obtained from the Danish Birth Register.

Surplus DBS samples collected for the Danish neonatal screening program have since 1981 been stored at $-25^{\circ} \mathrm{C}$ in a central repository (18). Samples in the repository were organized by date of birth and place of birth. The two samples placed closest to a case sample were selected as control samples matched by date- and place of birth. For the present study, two $3.2 \mathrm{~mm}$ DBS punches per case and control were available for analysis of islet autoantibodies.
The protocol was approved by the Danish ethical committee and the Danish Data Protection Agency. The study was conducted according to the principles expressed in the Declaration of Helsinki.

\section{Autoantibody assays}

GAD65A and IA-2A were determined in a previously described radiobinding assay (17). The DBSs were limited in availability, which made it necessary to combine ${ }^{35}$ S-methione-labeled GAD65 and IA-2 in one assay similar to previous reports (19). Islet autoantibody levels were measured in counts per minute. Relative units (RU) were calculated as described in detail elsewhere (20). Samples from matched cases and controls were always measured in the same assay run. In the present and in previous $(19,21)$ investigations of islet autoantibodies eluted from DBSs, the sensitivity for GAD65Ab and IA-2Ab assays was assessed in 1950 consecutively diagnosed (May 2005-September 2008) type 1 diabetes patients from all over Sweden. Using a cut-off value at $31 \mathrm{RU} / \mathrm{ml}$ (99.5 percentile for control population of Swedish children), we found that $1317 / 1950$ patients had GADA, i.e. representing 68\% diagnostic sensitivity. In the IA-2A assay, we used a cutoff value of $5 \mathrm{RU} / \mathrm{ml}$ (99.5 percentile for control population of Swedish children) and found that 1465/1950 patients had IA-2A representing 75\% sensitivity. Our laboratory participates in the Diabetes Autoantibody Standardization Program (DASP) (22), and in the 2007 serum exchange, the workshop sensitivity and specificity for GAD65Ab were 82 and $96 \%$ and the workshop sensitivity and specificity for IA-2Ab were 65 and 99\% respectively.

\section{Genotyping}

Time-resolved fluorometry was used for identification of HLA-DQB1 alleles (02, 0301, 0302, 0304, 0602, 0603, and 0604) as described in details (23).

\section{Statistical analysis}

We used conditional logistic regression for matched sets to analyze the data (SAS proc phreg). Because controls were sampled as being alive at the date of diagnosis of the case, the odds ratios from the analysis are estimates of hazard ratios (HRs) for type 1 diabetes.

Values of antibody measurements were $\log _{10}$ transformed in order to provide estimates of the effect of a tenfold increase of the antibody level.

Since case and control samples were matched by date of birth and hence age, date of sampling, and storage time, the effect of these variables cannot be assessed in this study. Interaction between autoantibody levels and these variables could in principle be assessed, but we have no reason to suspect that calendar time or storage 
time affects autoantibody levels differentially between cases and controls. Additional perinatal and demographic factors (BW, BL, GA, parental age, parental diabetes, and gender), and genotypes, were included into multiple regression models.

\section{Confounders}

Perinatal factors (BW, BL, and GA), demographic factors (parental age and gender), parental type 1 diabetes, and HLA-DQB1 genotype were considered possible confounders for the effect of islet autoantibodies on type 1 diabetes risk. Interaction models: the fact that the origin of islet autoantibodies detected in newborns most probably is of maternal origin was the rationale for testing for interaction between the effect of maternal type 1 diabetes and the presence of islet autoantibodies on type 1 diabetes risk. Separate effects for mothers with and without type 1 diabetes were considered.

\section{Results}

A total of $70 / 2023(3.5 \%)$ of the cases were positive in the GAD65A and IA-2A assays (HR $=7.49$, $P<0.0001)$. No significant change in frequency of antibody positivity and/or titers (measured in RU) by storage time could be detected (data not shown). The frequency of mothers and fathers with type 1 diabetes in the positive compared to negative islet autoantibody cases and controls is shown in Table 1. A total of 27 cases had mothers and 2 cases had fathers with type 1 diabetes compared to 8 and 1 respectively among the islet autoantibodies positive controls (n.s.). The HR 7.49 for positive islet autoantibodies status at birth decreased to HR 5.75 when controlling for parental diabetes. More islet autoantibody-positive cases, $27 / 70$ (39\%) than $27 / 1957(1.4 \%)$ islet autoantibody-negative cases $(P<0.0001)$, had a mother with type 1 diabetes.
Gender had no significant effect on the risk of developing type 1 diabetes. We also tested whether high-risk HLA-DQB1 alleles were confounders. The HR decreased to 4.55 but remained significant $(P<0.0003)$ after controlling for parental diabetes and HLA-DQB1 alleles.

The conditional logistic regression analysis showed a HR of 2.55 for every tenfold increase of RU in the GAD65A and IA-2A assays $(P<0.0001)$. We next analyzed whether perinatal and demographic factors modified the latter $\mathrm{HR}$ (Table 2). Not only maternal $(\mathrm{HR}=4.2 ; P<0.0001)$ but also paternal $(\mathrm{HR}=7.3 ; \mathrm{P}<0.001)$ diabetes patients were significant predictors, and also maternal age showed a significant effect $(\mathrm{HR}=1.2 / 10$ years; $P<0.03)$. Including parental type 1 diabetes and maternal age into the model reduced the type 1 diabetes risk from $\mathrm{HR} 2.55$ to HR 2.23; however, the risk remained significant $(P<0.0001)$. Including both $D Q B 1$ alleles as well as parental diabetes and maternal age into the model reduced the increased type 1 diabetes risk to HR 1.93, still indicating that islet autoantibody positivity had an independent risk $(P<0.001)$. There was no difference in autoantibody (aab) positivity in relation to age of type 1 diabetes diagnosis. In total, $57 \%$ of aab-positive cases were younger than 10 years of age $(20 \%<5$ years, 37\% 5-9 years), compared to all 1957 aab-negative cases, where the age distribution was similar: $58 \%$ of cases were diagnosed below 10 years of age $(24 \%<5$ years, 34\% 5-9 years).

\section{Discussion}

The present study shows that GAD65A and IA-2A positivity at birth were associated with a 7.5-fold increased risk for developing type 1 diabetes in this cohort of Danish children. Every tenfold increase in GAD65A and IA-2A levels at birth increased the risk for development of type 1 diabetes by a factor 2.55 . Thus, both presence and titers of GAD65A and IA-2A had a strong risk-increasing effect. Maternal type 1 diabetes

Table 1 Distribution of parental diabetes status per autoantibody status (in combined assay) and per case/control status. Diabetes status is subdivided into numbers of mothers and fathers with type 1 diabetes, with other types of diabetes (type 2 diabetes, latent autoimmune diabetes in adults (LADA), gestational diabetes), unspecified diabetes (uncertain of diabetes type), or without diabetes (no).

\begin{tabular}{|c|c|c|c|c|c|c|c|c|}
\hline \multirow{4}{*}{$\begin{array}{l}\text { Diabetes } \\
\text { status }\end{array}$} & \multicolumn{8}{|c|}{ Autoantibody status (combined) } \\
\hline & \multicolumn{4}{|c|}{ Cases } & \multicolumn{4}{|c|}{ Controls } \\
\hline & \multicolumn{2}{|c|}{ Positive } & \multicolumn{2}{|c|}{ Negative } & \multicolumn{2}{|c|}{ Positive } & \multicolumn{2}{|c|}{ Negative } \\
\hline & Mothers & Fathers & Mothers & Fathers & Mothers & Fathers & Mothers & Fathers \\
\hline Type 1 & 27 & 2 & 27 & 120 & 8 & 1 & 14 & 37 \\
\hline Other & 3 & 1 & 21 & 25 & 1 & 0 & 36 & 44 \\
\hline No & 40 & 67 & 1904 & 1804 & 12 & 20 & 3969 & 3936 \\
\hline Unspecified & 0 & 0 & 2 & 5 & 0 & 0 & 2 & 4 \\
\hline Unknown & 0 & 0 & 3 & 3 & 0 & 0 & 0 & 0 \\
\hline Total $(n)$ & 70 & 70 & 1957 & 1957 & 21 & 21 & 4021 & 4021 \\
\hline
\end{tabular}

Altogether (cases + controls) there were 6069 mothers and 6069 fathers. 
Table 2 Inclusion of perinatal data and parental diabetes. The variables in the table may be responsible for some of the effects on type 1 diabetes risk falsely ascribed to the presence of autoantibodies, i.e. may be confounders.

\begin{tabular}{lcll}
\hline Variables & $\begin{array}{c}\text { Hazard } \\
\text { ratio (HR) }\end{array}$ & \multicolumn{1}{c}{$\mathbf{9 5 \%} \mathbf{C l}$} & \multicolumn{1}{c}{$\boldsymbol{P}<$} \\
\hline $\begin{array}{l}\text { Tenfold increase in RU } \\
\quad \text { autoantibodies }\end{array}$ & 2.23 & $1.66-3.01$ & 0.0001 \\
Birth length - per cm & 0.91 & $0.97-1.04$ & 0.91 \\
Birth weight - per kg & 1.03 & $0.87-1.23$ & 0.71 \\
Gestational age - per week & 1.00 & $0.95-1.04$ & 0.84 \\
Maternal age - per 10 years & 1.22 & $1.02-1.489$ & 0.03 \\
Paternal age - per 10 years & 0.93 & $0.80-1.09$ & 0.37 \\
Sex, male versus female & 1.05 & $0.93-1.20$ & 0.42 \\
Maternal type 1 diabetes & 4.23 & $2.29-7.81$ & 0.0001 \\
Paternal type 1 diabetes & 7.31 & $4.71-11.35$ & 0.0001 \\
\hline
\end{tabular}

By inclusion into the statistical model, the individual increases/decreases in type 1 diabetes risk belonging to each variable are listed including the level of significance ( $P$ value) and confidence interval $(\mathrm{Cl})$.

was a confounder, but it was only responsible for approximately one-fifth of the risk increase associated with GAD65A and IA-2A presence. That the presence of islet autoantibodies at the time of birth may be predictive for later type 1 diabetes development was suggested by Lindberg et al. (4), who studied cord blood samples from 85 children who later developed type 1 diabetes and 321 control subjects. Our approach to test the validity of the previous observation (4) was to utilize the unique repository of DBS samples collected for the Danish neonatal screening program since 1981 (17, 18). This repository, unique in that the DBSs have been stored at $-25^{\circ} \mathrm{C}$, made it possible to study samples from 2023 type 1 diabetes cases and 4046 matched controls. The present study is to our knowledge the first to show in a large, validated, and population-based case-control investigation that islet autoantibodies at birth were associated with increased type 1 diabetes risk later in life.

Do the islet autoantibodies identified in the 5-day-old newborns have maternal origin or are they produced by the newborn themselves? It is well known that during second trimester of pregnancy, maternal immunoglobulin is actively transported across the placenta to the fetus (24). Antibody transport accelerates during the last trimester until birth, and IgG concentrations in the fetus exceed those of the mother (25). Neither maternal IgA nor IgM are transferred to the fetus. In the present study, detected GAD65A and IA-2A were mostly of the IgG subclass as Sepharose Protein A was used to separate free from antibody-bound labeled autoantigen. From vaccination studies (26), it is known that the ability of newborns to generate IgG responses increases over the first year, but adult responses to protein antigens are not achieved until 12-24 months of age. We assume that the GAD65A and IA-2A we measured were transferred from the mother to the child. It is therefore possible that subclinical islet autoimmunity in the pregnant mother may explain the increased risk for type 1 diabetes in her offspring.
Islet autoantibodies are strongly associated with HLA-conferred diabetes susceptibility both in families and in the general population (27). We asked whether autoantibody positivity is a surrogate marker of HLAdefined diabetes predisposition in the current study population. It is likely that the autoantibody-positive non-diabetic mothers carry HLA risk genotypes for type 1 diabetes at a higher frequency than the autoantibodynegative mothers. Accordingly, the autoantibodypositive mothers may also transfer such genotypes to their child resulting in an increased diabetes risk in the offspring. The type 1 diabetes risk ascribed to the presence of GAD65A and IA-2A was reduced but still remaining significant when $H L A-D Q B 1$ genotypes were included into the model. It cannot be excluded that other genetic factors, with lower risk, may contribute to the risk of type 1 diabetes in the offspring to islet autoantibody-positive mothers. We conclude that the presence of islet autoantibodies at the time of birth predicts type 1 diabetes risk regardless of HLA risk genotypes and maternal diabetes.

In the present study, only one-fifth of the increase in disease risk related to the presence of GAD65A and IA$2 \mathrm{~A}$ was actually related to maternal diabetes. However, GAD65A- and IA-2A-positive cases without diabetic mothers may be the most intriguing observation. Follow-up studies of these mothers will be of interest as gestational islet autoantibodies may increase the risk for post partum type 1 diabetes $(28,29)$. In these mothers, in utero infections (30) or other stressors (14) could either have had direct impact on $\beta$ cells or may have caused $\beta$-cell damage by initiating a strong proinflammatory immune response. Furthermore, about $50 \%$ of those children whose mothers have type 1 diabetes were still GAD65A and IA-2A negative at the time of birth. Mothers diagnosed with type 1 diabetes have variable duration of their diabetes, and may become negative for autoantibodies prior to or during their pregnancy (31).

A possible weakness to our study is that we may in particular detect cases that had an early age at diagnosis. However, the GAD65A- and IA-2A-related effect on type 1 diabetes risk was found to be similar in children below and above 10 years of age at type 1 diabetes onset. Proportions of GAD65A- and IA-2Apositive cases with young diagnosis out of all GAD65Aand IA-2A-positive cases, and of young GAD65A- and IA-2A-positive cases out of all cases, were similar. In the DIPP study (27), the majority of children who developed first multiple islet autoantibodies and then type 1 diabetes had an appearance of one or more islet autoantibody below the age of 5 years. In the DAISY study (11), no association could be shown between the presence of islet autoantibodies at birth and type 1 diabetes risk. In the BABY DIAB study (10), in contrast, the presence of maternal islet autoantibodies was suggested as protective against type 1 diabetes before the age of 8 years. Insulin autoantibodies (IAA) 
persisting after the age of 8 months of age (12), on the other hand, were associated with an increased type 1 diabetes risk. Owing to limited DBS material, we were also not able to analyze IAA in the present study. Much larger cohort studies will be needed to further analyze the risk of islet autoantibodies at the time when DBSs are obtained for perinatal screening of monogenic diseases. In such studies, it will also be important to obtain data on maternal islet autoantibodies as well as HLA alleles and non-HLA genetic risk factors (2, 32). The individually matched case-control design implies that control subjects were selected as not having diabetes at the date of diagnosis of the corresponding case. None of the control subjects developed type 1 diabetes in the follow-up period; nevertheless, we cannot exclude some subjects of the control group, which may develop type 1 diabetes later in life. However, this is unlikely to affect the overall conclusion of the study.

In the present case cohort, specificity was very high, i.e. seven times as many future type 1 diabetes patients were GAD65A and/or IA-2A positive at birth compared to the control group. Because the number of cases and controls in our study population does not correspond to the real distribution in a background population (i.e. the ratio of cases to controls in the study is much higher), we are not able to draw conclusions for how specific and sensitive the presence of GAD65A and IA-2A at birth were for prediction of type 1 diabetes in the general population.

In conclusion, the present study represents a large population-based case-control study demonstrating that GAD65A and IA-2A positivity at birth suggest an increased risk of developing type 1 diabetes at any age before 23 years.

\section{Declaration of interest}

The authors declare that there is no conflict of interest that could be perceived as prejudicing the impartiality of the research reported.

\section{Funding}

The prediction study was supported by grants from Danish Medical Research Council, P Carl Petersen Foundation, Danish Diabetes Association, $\mathrm{P}$ and E Sehested Hansen's Foundation, E and Å Danielsen's Foundation, Novo Nordisk Foundation, Ragnhild Ibsen's Foundation for Medical Research, Mr and Mrs Director Leo Nielsen's Foundation, Bernhard and Marie Klein's Foundation, Foundation of the Danish Medical Association, and M C and J K Moltum's Foundation. Autoantibody analyses were supported in part by the Swedish Research Council, Knut and Alice Wallenberg Foundation, and Skåne County Council for Research and Development.

\section{Acknowledgements}

Jannet Svensson, Karin Marinelli, and the Danish Study Group for Childhood Diabetes are acknowledged for their help with data validation. We thank Rikke Bonne (SDC) and Britt Buveris-Svenburg (CRC Malmö) for technical and Kristian Lynch (CRC Malmö) for statistical assistance.

\section{References}

1 Pundziute-Lycka A, Dahlquist G, Nystrom L, Arnqvist H, Bjork E, Blohme G, Bolinder J, Eriksson JW, Sundkvist G \& Ostman J. The incidence of type I diabetes has not increased but shifted to a younger age at diagnosis in the 0-34 years group in Sweden 1983-1998. Diabetologia 200245 783-791. (doi:10.1007/ s00125-002-0845-2)

2 Barrett JC, Clayton DG, Concannon P, Akolkar B, Cooper JD, Erlich HA, Julier C, Morahan G, Nerup J, Nierras C, Plagnol V, Pociot F, Schuilenburg H, Smyth DJ, Stevens H, Todd JA, Walker NM \& Rich SS. Genome-wide association study and meta-analysis find that over 40 loci affect risk of type 1 diabetes. Nature Genetics 200941 703-707. (doi:10.1038/ng.381)

3 Pociot F, Akolkar B, Concannon P, Erlich HA, Julier C, Morahan G, Nierras CR, Todd JA, Rich SS \& Nerup J. Genetics of type 1 diabetes: what's next? Diabetes 201059 1561-1571. (doi:10.2337/db100076)

4 Lindberg B, Ivarsson SA \& Lernmark A. Islet autoantibodies in cord blood could be a risk factor for future diabetes. Diabetologia 199942 1375. (doi:10.1007/s001250051137)

5 Ong KK, Petry CJ, Barratt BJ, Ring S, Cordell HJ, Wingate DL, Pembrey ME, Todd JA \& Dunger DB. Maternal-fetal interactions and birth order influence insulin variable number of tandem repeats allele class associations with head size at birth and childhood weight gain. Diabetes 200453 1128-1133. (doi:10. 2337/diabetes.53.4.1128)

6 Peng H \& Hagopian W. Environmental factors in the development of type 1 diabetes. Reviews in Endocrine and Metabolic Disorders 20067 149-162. (doi:10.1007/s11154-006-9024-y)

7 Knip M \& Siljander H. Autoimmune mechanisms in type 1 diabetes. Autoimmunity Reviews 20087 550-557. (doi:10.1016/j. autrev.2008.04.008)

8 Notkins AL \& Lernmark A. Autoimmune type 1 diabetes: resolved and unresolved issues. Journal of Clinical Investigation $2001 \mathbf{1 0 8}$ 1247-1252. (doi:10.1172/JCI14257)

9 Knip M, Korhonen S, Kulmala P, Veijola R, Reunanen A, Raitakari OT, Viikari J \& Akerblom HK. Prediction of type 1 diabetes in the general population. Diabetes Care 201033 1206-1212. (doi:10.2337/dc09-1040)

10 Koczwara K, Bonifacio E \& Ziegler AG. Transmission of maternal islet antibodies and risk of autoimmune diabetes in offspring of mothers with type 1 diabetes. Diabetes 200453 1-4. (doi:10. 2337/diabetes.53.1.1)

11 Stanley HM, Norris JM, Barriga K, Hoffman M, Yu L, Miao D, Erlich HA, Eisenbarth GS \& Rewers M. Is presence of islet autoantibodies at birth associated with development of persistent islet autoimmunity? The Diabetes Autoimmunity Study in the Young (DAISY) Diabetes Care 200427 497-502. (doi:10.2337/ diacare.27.2.497)

12 Naserke HE, Bonifacio E \& Ziegler AG. Prevalence, characteristics and diabetes risk associated with transient maternally acquired islet antibodies and persistent islet antibodies in offspring of parents with type 1 diabetes. Journal of Clinical Endocrinology and Metabolism 2001 86 4826-4833. (doi:10.1210/jc.86.10.4826)

13 Hamalainen AM, Ronkainen MS, Akerblom HK \& Knip M. Postnatal elimination of transplacentally acquired disease-associated antibodies in infants born to families with type 1 diabetes. The Finnish TRIGR Study Group. Trial to reduce IDDM in the genetically at risk. Journal of Clinical Endocrinology and Metabolism 200085 4249-4253. (doi:10.1210/jc.85.11.4249)

14 Dahlquist G \& Kallen B. Maternal-child blood group incompatibility and other perinatal events increase the risk for early-onset type 1 (insulin-dependent) diabetes mellitus. Diabetologia 199235 671-675. (doi:10.1007/BF00400261)

15 Larsson HE, Lynch K, Lernmark B, Hansson G, Lernmark A \& Ivarsson SA. Relationship between increased relative birthweight and infections during pregnancy in children with a high-risk diabetes HLA genotype. Diabetologia 200750 1161-1169. (doi:10.1007/s00125-007-0648-6) 
16 Svensson J, Carstensen B, Mortensen HB \& Borch-Johnsen K. Early childhood risk factors associated with type 1 diabetes - is gender important? European Journal of Epidemiology 200520 429-434. (doi:10.1007/s10654-005-0878-1)

17 Eising S, Svensson J, Skogstrand K, Nilsson A, Lynch K, Andersen PS, Lernmark A, Hougaard DM, Pociot F, NorgaardPedersen B \& Nerup J. Type 1 diabetes risk analysis on dried blood spot samples from population-based newborns: design and feasibility of an unselected case-control study. Paediatric and Perinatal Epidemiology 200721 507-517. (doi:10.1111/j.13653016.2007.00846.x)

18 Norgaard-Pedersen B \& Hougaard DM. Storage policies and use of the Danish Newborn Screening Biobank. Journal of Inherited Metabolic Disease 200730 530-536. (doi:10.1007/s10545-0070631-x)

19 Lynch KF, Lernmark B, Merlo J, Cilio CM, Ivarsson SA \& Lernmark A. Cord blood islet autoantibodies and seasonal association with the type 1 diabetes high-risk genotype. Journal of Perinatology 200828 211-217. (doi:10.1038/sj.jp.7211912)

20 Grubin CE, Daniels T, Toivola B, Landin-Olsson M, Hagopian WA, Li L, Karlsen AE, Boel E, Michelsen B \& Lernmark A. A novel radioligand binding assay to determine diagnostic accuracy of isoform-specific glutamic acid decarboxylase antibodies in childhood IDDM. Diabetologia 199437 344-350. (doi:10.1007/BF00408469)

21 Papadopoulou A, Lynch KF, Shaat N, Nilsson A, Lernmark B Berntorp K, Ivarsson SA, Agardh CD \& Lernmark A. The type 1 diabetes protective HLA DQB $1 * 0602$ allele is less frequent in gestational diabetes mellitus. Diabetologia 200952 1339-1342. (doi:10.1007/s00125-009-1351-6)

22 Torn C, Mueller PW, Schlosser M, Bonifacio E \& Bingley PJ. Diabetes Antibody Standardization Program: evaluation of assays for autoantibodies to glutamic acid decarboxylase and islet antigen-2. Diabetologia 200851 846-852. (doi:10.1007/s00125-008-0967-2)

23 Sjoroos M, Iitia A, Ilonen J, Reijonen H \& Lovgren T. Triple-label hybridization assay for type-1 diabetes-related HLA alleles. Biotechniques $1995 \mathbf{1 8} 870-877$.

24 Simister NE. Placental transport of immunoglobulin G. Vaccine 200321 3365-3369. (doi:10.1016/S0264-410X(03)00334-7)

25 Malek A, Sager R, Kuhn P, Nicolaides KH \& Schneider H. Evolution of maternofetal transport of immunoglobulins during human pregnancy. American Journal of Reproductive Immunology 199636 248-255.
26 Gans H, DeHovitz R, Forghani B, Beeler J, Maldonado Y \& Arvin AM. Measles and mumps vaccination as a model to investigate the developing immune system: passive and active immunity during the first year of life. Vaccine $2003 \mathbf{2 1}$ 3398-3405. (doi:10.1016/S0264-410X(03)00341-4)

27 Kukko M, Kimpimaki T, Korhonen S, Kupila A, Simell S, Veijola R, Simell T, Ilonen J, Simell O \& Knip M. Dynamics of diabetesassociated autoantibodies in young children with human leukocyte antigen-conferred risk of type 1 diabetes recruited from the general population. Journal of Clinical Endocrinology and Metabolism 200590 2712-2717. (doi:10.1210/jc.2004-1371)

28 Nilsson C, Ursing D, Torn C, Aberg A \& Landin-Olsson M. Presence of GAD antibodies during gestational diabetes mellitus predicts type 1 diabetes. Diabetes Care 200730 1968-1971. (doi:10. 2337/dc07-0157)

29 Ivarsson SA, Ackefors M, Carlsson A, Ekberg G, Falorni A, Kockum I, Landin-Olsson M, Lernmark A, Lindberg B, Sundkvist G \& Svanberg L. Glutamate decarboxylase antibodies in non-diabetic pregnancy precedes insulin-dependent diabetes in the mother but not necessarily in the offspring. Autoimmunity 199726 261-269. (doi:10.3109/08916939709008032)

30 Dahlquist GG, Ivarsson S, Lindberg B \& Forsgren M. Maternal enteroviral infection during pregnancy as a risk factor for childhood IDDM. A population-based case-control study. Diabetes 199544 408-413. (doi:10.2337/diabetes.44.4.408)

31 Novak EJ, Ortqvist E, Nord E, Edwall L, Hampe CS, Bekris L, Persson BE \& Lernmark A. Stability of disease-associated antibody titers in pregnant women with type 1 diabetes with or without residual $\beta$-cell function. Diabetes Care 200023 1019-1021. (doi:10.2337/diacare.23.7.1019)

32 Concannon P, Chen WM, Julier C, Morahan G, Akolkar B, Erlich HA, Hilner JE, Nerup J, Nierras C, Pociot F, Todd JA \& Rich SS. Genome-wide scan for linkage to type 1 diabetes in 2,496 multiplex families from the Type 1 Diabetes Genetics Consortium. Diabetes 200958 1018-1022. (doi:10.2337/db081551)

Received 10 November 2010

Accepted 19 November 2010 